\title{
Duration of Breastfeeding and Its Correlates in Bangladesh
}

\author{
Shamima Akter and Md. Mizanur Rahman
}

Department of Population Science and Human Resource Development, University of Rajshahi, Rajshahi 6205, Bangladesh

\begin{abstract}
The purpose of this study was to assess the duration of breastfeeding and the sociodemographic factors affecting it. Data for the study were drawn from the Bangladesh Demographic and Health Survey 2004. In total 5,364 mothers were included in the study. The life table and Cox's proportional hazards model were employed for the analysis of breastfeeding-related data, which showed that the average duration of breastfeeding was 31.9 months. Cox regression analysis revealed that the duration of breastfeeding was positively associated with maternal age, contraceptive-use, work status, and religion and was negatively associated with age at marriage, parity, delivery status, region, and maternal education. Younger mothers, having higher education, higher maternal parity, caesarean-section birth, being a Muslim, and mothers who have not used any contraceptive were associated with lower duration of breastfeeding. The findings suggest that health institutions can play a significant role in promoting breastfeeding in Bangladesh. Educational campaigns that stress the benefits of lactation are important strategies for encouraging mothers to breastfeed longer.
\end{abstract}

Key words: Breastfeeding; Parity; Sociodemographic factors; Bangladesh

\section{INTRODUCTION}

Breastfeeding plays a vital and influential role on the duration of amenorrhoea, child survival, and fertility, offering protection to an infant against early morbidity and mortality. Short-term risks of not breastfeeding include an increased risk of postpartum haemorrhage while long-term effects may include a higher risk of osteoporosis and breast and ovarian cancers (1). Breastmilk contains all types of nutrients required for an infant in right proportion and composition (2).

Longer and more frequent breastfeeding and maternal survival status ensure the survival of children (3-4). Results of studies on cessation of breastfeeding of children suggest that mothers who have lower education stop breastfeeding earlier than those with higher education (5-7). Other factors that also relate to the duration of breastfeeding are

Correspondence and reprint requests should be addressed to:

Md. Mizanur Rahman

Assistant Professor

Department of Population Science and

Human Resource Development

University of Rajshahi

Rajshahi 6205

Bangladesh

Email: mizanur_rub@yahoo.com present age of mothers and socioeconomic status (7-12). Younger mothers are most likely to terminate breastfeeding early compared to older counterparts (13-15).

The importance of breastfeeding in regulating individual and social fertility has been a matter of general interest for many years because it tends to increase the average birth interval and, therefore, to reduce women's fertility over their life span, especially in societies where the use of contraceptive methods is not widespread. Recent reviews and meta-analyses conclude that breastfeeding constitutes a small but consistent protective effect against obesity or higher values of body mass index (BMI) in children (16-19).

The propensity to breastfeed is not only of importance with regard to the beneficial effects on individuals but is also of concern as an indicator of health behaviour relating to social conditions. A large body of research supports an association between the socioeconomic status and the health and development of children (20-24) but this concept has rarely been studied in relation to the duration of breastfeeding in the context of Bangladesh. The aim of this paper was to estimate the duration of breastfeeding and also to explore the sociodemographic determinants of the duration of breastfeeding in Bangladesh. 


\section{MATERIALS AND METHODS}

Data for the study were drawn from the Bangladesh Demographic and Health Survey (BDHS) 2004. Information was collected on education, age, reproductive behaviour, availability of family-planning supplies and services, breastfeeding, child health, and maternal status. The survey considered ever-married women of reproductive age as eligible for interview. A sample of 10,500 households was selected from which 11,444 women were interviewed. In total, 5,364 mothers provided information on the duration of breastfeeding for their lastborn child at the time of interview. The maximum number of months of breastfeeding recorded in the survey was 60 but our study included the duration of breastfeeding up to 48 months and ignored the remaining months as outlier.

\section{Measurement of variables}

\section{Dependent variable}

The duration of breastfeeding the last child of the respondent was the dependent variable which was calculated as the number of months that the mother reports having breastfed the child.

\section{Independent variables}

The demographic variables included age of mother, age-at-marriage, sex of child, parity, contraceptiveuse, and delivery status.

For analysis of data, the age of the respondent was categorized into three broad groups: $\leq 24$ years, $25-$ 34 years, and 35 years and over. The age-at-marriage was classified into four categories: $\leq 14$ years, $15-19$ years, $20-24$ years, and 25 years and over. The parity of mother in the sample was divided into four major groups: $1,2,3-5$, and $\geq 6$. The category relating to contraceptive-use was dichotomous: not used and used. The delivery status was assessed as either normal or by caesarean section.

The socioeconomic variables included place of residence, region of residence/administrative division, the highest level of education of the respondent and the husband, and occupation of the respondent.

Education of the respondent is the highest level of schooling attained, measured as no education, primary, secondary, and higher; education of her spouse was also measured as no education, primary, secondary, and higher. Occupation of the respondent was also measured as a categorical variable: not working and professional/administrative, clerical/sales, skilled/unskilled manual, domestic, and others.

\section{Statistical analysis}

Bivariate and multivariate statistical techniques were used for studying the predictor variableduration of breastfeeding - in relation to the explanatory variables. The variable-duration of breastfeeding-was coded as 0-12 months, 12-24 months, 24-36 months, and 36-48 months. The association of the duration of breastfeeding with all the independent variables in the study was first checked by the chi-square statistic. Life-table analysis provides a good understanding of breastfeeding behaviour over time. The factors affecting the duration of breastfeeding were investigated in a regression using Cox's proportional hazard model (25). This model was used for determining the covariates that were significantly associated with the duration of breastfeeding. The data obtained were analyzed using the SPSS software (version 10.0 (26), Statistica 5.0, and Excel.

\section{Life-table technique}

A life-table can be constructed by pooling completed and censored cases of breastfeeding (27-28). The completed observations were those in which breastfeeding was stopped, and the exact duration of breastfeeding was known. Censored observations were those in which the child was still being breastfed at the time of survey. The mean duration of breastfeeding was used as the summary measures.

\section{Cox's proportional hazard model}

Survival analysis technique was used in analyzing breastfeeding-related data. The survival analysis technique adjusts for truncation bias by incorporating both complete and incomplete segments of histories in the analysis of breastfeeding-related data (some mothers might be continuing to breastfeed at the time of the survey). The Cox's proportional hazards (PH) model may be viewed as a multivariate life-table but unlike other regression techniques, this method uses censored data and, thus, controls for truncation bias (29). Descriptive statistics and the individual effects of Cox regression analysis for each variable are given to provide a general overview of the covariates in the analysis (30). The hazard function at time-point $t$ (stopping or termination of breastfeeding), denoted $\lambda(\mathrm{t}, \mathrm{z})$, by is expressed as: $\lambda(\mathrm{t}, \mathrm{z})=\lambda_{0}(t) \cdot \exp \sum \mathrm{X}_{\mathrm{i}} \beta_{\mathrm{i}}$, where $\lambda(\mathrm{t}, \mathrm{z})$ is the hazard rate at time $t, \lambda_{0}(t)$ is the baseline hazard function of $\mathrm{t}, \beta_{i}$ is a vector of coefficients, and $X_{i}$ is a vector of covariates. It is assumed in this model that: (a) there is a hazard or risk of occurrence of the event of interest (in this case, the 
termination of breastfeeding) at each time $t$, and this is applicable to all members of the population; (b) at each time $t$, the respondents at one level of a given subgroup experience a hazard proportional to the reference category; the models are a function of time and regressor variables; and (c) there will only be one set of coefficients. The hazard ratio (odds ratio) for breastfeeding and its 95\% confidence interval (CI) were calculated for the sociodemographic factors associated with breastfeeding.

\section{RESULTS}

The figure shows the overall pattern of breastfeeding in Bangladesh. The survival curve represents the probability of mothers who continued to breastfeed at any given time. During the first month of life, the maximum (87\%) probability of continuing breastfeeding was observed, which decreased dramatically after two years of age.

The life-table analysis and its related measure (mean) for the duration of breastfeeding by various covariates of mother and child are shown in Table 1. Bivariate analysis revealed significant differences in the duration of breastfeeding relating to place of residence, administrative division, delivery status, contraceptive-use, education of mother, education of husband, parity, and religion.

The mean duration of breastfeeding in Bangladesh for surviving children is 31.9 months. It is comparatively higher among younger mothers ( $<25$ years) than older mothers ( $\geq 35$ years). In this study, the mean duration of breastfeeding was 32.67 months for mothers of younger age-group, 31.4 months for middle-aged mothers, and 31.6 months for older mothers. Mothers who were married at an early age had a longer duration of breastfeeding than those who were married in older age. Mothers of single parity breastfed their children, on average, for 32.4 months; mothers of 2 parity breastfed for

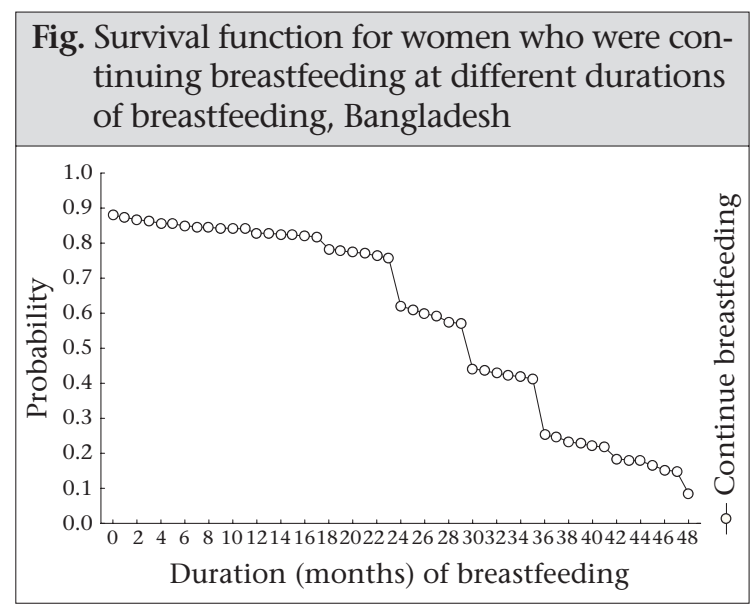

\begin{tabular}{|c|c|c|c|}
\hline & & & $\mathrm{p}$ value \\
\hline $\begin{array}{l}\text { Age (years) of } \\
\text { mothers }\end{array}$ & & & \\
\hline$\leq 24$ & 2,659 & 32.69 & \\
\hline $25-34$ & 2,217 & 31.42 & \\
\hline 35 and above & 579 & 31.63 & 0.128 \\
\hline $\begin{array}{l}\text { Age-at-marriage } \\
\text { (years) }\end{array}$ & & & \\
\hline$\leq 14$ & 2,745 & 32.70 & \\
\hline $15-19$ & 2,337 & 31.49 & \\
\hline $20-24$ & 323 & 30.53 & \\
\hline $25+$ & 50 & 28.85 & 0.007 \\
\hline $\begin{array}{l}\text { Sex of previous } \\
\text { child }\end{array}$ & & & \\
\hline Male & 2,774 & 32.00 & \\
\hline Female & 2,681 & 31.99 & 0.879 \\
\hline Parity & & & \\
\hline 1 & 1,529 & 32.42 & \\
\hline 2 & 1,375 & 32.04 & \\
\hline $3-5$ & 1,967 & 32.13 & \\
\hline 6 and above & 584 & 31.82 & 0.005 \\
\hline Contraceptive- & & & \\
\hline use & & & \\
\hline Not using & 917 & 31.47 & \\
\hline Currently using & 4,538 & 32.13 & 0.000 \\
\hline Delivery status & & & \\
\hline Normal & 5,189 & 32.13 & \\
\hline Caesarian & 266 & 30.12 & 0.000 \\
\hline $\begin{array}{l}\text { Place of resi- } \\
\text { dence }\end{array}$ & & & \\
\hline Urban & 1,707 & 30.51 & \\
\hline Rural & 3,749 & 32.71 & 0.000 \\
\hline Division/region & & & \\
\hline Barisal & 619 & 32.83 & \\
\hline Chittagong & 1,129 & 27.78 & \\
\hline Dhaka & 1,224 & 32.25 & \\
\hline Khulna & 725 & 33.79 & \\
\hline Rajshahi & 1,101 & 33.72 & \\
\hline Sylhet & 657 & 32.16 & 0.000 \\
\hline $\begin{array}{l}\text { Education of } \\
\text { mothers }\end{array}$ & & & \\
\hline No education & 1,924 & 32.60 & \\
\hline Primary & 1,675 & 32.96 & \\
\hline Secondary & 1,524 & 30.71 & \\
\hline Higher & 338 & 29.90 & 0.013 \\
\hline $\begin{array}{l}\text { Work status of } \\
\text { respondents }\end{array}$ & & & \\
\hline Working & 998 & 32.25 & \\
\hline Not-working & 4,457 & 31.90 & 0.218 \\
\hline
\end{tabular}




\begin{tabular}{|lccc|}
\hline Table 2-Contd. & & & \\
\hline Characteristics & No. & Mean & p value \\
\hline $\begin{array}{l}\text { Education of } \\
\text { husband }\end{array}$ & & & \\
$\quad \begin{array}{l}\text { No education } \\
\quad 2,035\end{array}$ & 33.01 & \\
$\quad$ Primary & 1,466 & 32.35 & \\
$\quad \begin{array}{l}\text { Secondary } \\
\quad \text { and higher }\end{array}$ & 1,954 & 30.65 & 0.004 \\
Religion & & & \\
$\quad$ Muslim & 4,962 & 31.53 & \\
$\quad$ Non-Muslim & 493 & 36.13 & 0.062 \\
Bangladesh & 5,455 & 31.99 & - \\
\hline
\end{tabular}

32.0 months; and those with 3-5 parity breastfed for 32.1 months. This decreased to 31.8 months for those who had six and more children. The average duration of breastfeeding was 31.4 months for mothers who were not using any contraception compared to 32.1 months for those who were using contraception. The mean duration of breastfeeding was comparatively lower among mothers who gave birth by caesarean section (30.1 months) compared to mothers giving birth vaginally (32.1 months).

The urban mothers breastfed their children for a relatively-shorter duration than did the rural mothers. Among the six administrative divisions of Bangladesh, the duration of breastfeeding was the lowest in Chittagong division (27.78 months). The non-Muslim mothers breastfed for a longer duration (36.13 months) than the Muslim mothers (31.53 months).

Table 2 presents the results of the proportionality hazards model for the duration of breastfeeding. Age of mother, age-at-marriage, parity, contraceptive-use, delivery status, region, religion, education and occupation of mother were statistically significant. The odds of stopping breastfeeding for older mothers were lower than their younger counterparts. Women who married at an early age $(\leq 14$ years) had a lower risk of stopping breastfeeding compared to women who married at an older age (25 years and over). Increased parity was associated with increase in the risk of cessation of breastfeeding. Normal delivery was associated with a $23 \%$ less likelihood of terminating breastfeeding compared to birth by caesarean section. Similarly, the use of contraceptives had a lower risk of stopping breastfeeding. The mothers of Chittagong and Sylhet divisions were more likely to terminate breastfeeding early compared to the mothers in other divisions. The Muslim mothers had 1.3 times higher risk of stopping breastfeeding than their non-Muslim peers. The risk of cessation of breastfeeding increased with increasing maternal education. Moth-
Table 2. Cox's proportional hazard model estimates of relative risk of sociodemographic characteristics on cessation of breastfeeding, Bangladesh, 2004

\begin{tabular}{|lcc|}
\hline Explanatory variable & $\begin{array}{c}\text { Odds } \\
\text { ratio }\end{array}$ & $\begin{array}{c}95 \% \\
\text { CI }\end{array}$ \\
\hline Age (years) of mothers & & \\
$\leq 24$ & $2.114^{*}$ & $1.851-2.414$ \\
$25-34$ & $1.386^{*}$ & $1.239-1.551$ \\
$35+$ & 1.000 & \\
Age-at-marriage & & \\
(years) & & \\
$\leq 14$ & $0.593^{*}$ & $0.439-0.801$ \\
$15-19$ & $0.634^{*}$ & $0.471-0.853$ \\
$20-24$ & $0.699^{* *}$ & $0.513-0.954$ \\
$25+$ & 1.000 & \\
\hline
\end{tabular}

Sex of child

Male

0.971

Female

1.000

Parity

1

$0.632^{\star}$

$0.919-1.026$

2

3-5

$0.691^{*}$

0.545-0.733

0.991

0.603-0.790

$6+$

1.000

Contraceptives-use

No used

Used

$1.387^{*}$

1.000

Delivery status

Normal

$0.767^{\star}$

Caesarean

1.000

$0.669-0.881$

Place of residence

Urban

1.007

Rural

1.000

Division/region

Barisal

Chittagong

Dhaka

Khulna

Rajshahi

Sylhet

$0.874^{\star *}$

$1.133^{* *}$

$0.903^{\star * *}$

0.929

0.813-1.022

Religion

Muslim

Non-Muslim

$0.861^{*}$

1.000

$1.289^{*}$

1.000

1.169-1.422

Educational level

No-education

Primary

Secondary

Higher

$0.790^{*}$

$0.820^{*}$

$0.891^{* *}$

1.000

0.680-0.917

$0.712-0.943$

0.782-1.015

Work status

Do not work

$1.161^{*}$

1.079-1.249

Work 


\begin{tabular}{|lcc|}
\hline Table 2-Contd. & & \\
\hline Explanatory variable & $\begin{array}{c}\text { Odds } \\
\text { ratio }\end{array}$ & $\begin{array}{c}\text { 95\% } \\
\text { CI }\end{array}$ \\
\hline $\begin{array}{l}\text { Education of } \\
\text { husband }\end{array}$ & & \\
$\quad$ No education & 0.997 & $0.920-1.079$ \\
$\quad$ Primary & 1.002 & $0.927-1.083$ \\
$\quad$ Secondary and & & \\
$\quad$ higher & 1.000 & \\
Log-likelihood & $77,191.721$ & \\
Model chi-square & 405.96 & \\
Degrees of freedom & 24 \\
p value & 0.000 \\
\hline "p $<0.01 ;{ }^{* *} \mathrm{p}<0.05 ;{ }^{* * *} \mathrm{p}<0.10$, significant variables \\
in the model; CI=Confidence interval \\
\hline
\end{tabular}

ers not working were 1.16 times more likely to stop breastfeeding than working mothers.

\section{DISCUSSION}

The study examined the socioeconomic and demographic determinants of breastfeeding in Bangladesh. Breastfeeding is virtually universal (98.3\%) and prolonged in Bangladesh. Past studies in Bangladesh found the mean duration of breastfeeding to be 26.4-28.9 months (30-33). It seems that the duration of breastfeeding in Bangladesh is gradually increasing.

Increasing maternal age and parity can lead to breastfeeding of a shorter duration. Higher parity leads to shorter birth intervals and, hence, shorter time available for breastfeeding. It is also wellestablished that parity is closely related to maternal age (31). An older woman is more likely to have a greater number of children; hence, the demand on her time is considerable which may lead to early termination of breastfeeding. Poor nutritional status, particularly among older women, can diminish the capacity and the fat and vitamin content of breastmilk. The result is that not enough breastmilk will be provided to the infant, thus, hastening early termination of breastfeeding. In this study, mothers with 1,2 , and $3-5$ parity were $37 \%, 31 \%$, and $1 \%$ less likely to terminate breastfeeding than mothers with $\geq 6$ parity, suggesting that an increase in parity is associated with a decrease in probability of terminating breastfeeding. Giving births to too many children might have caused physical complications and weakness to these mothers who were unable to breastfeed their children. Women aged $\leq 14$ years, $15-19$ years, and 20-24 years were less likely to terminate breastfeeding than women who were married at $\geq 25$ years. The higher risk of terminating breastfeeding in mothers with first-born babies might result from two reasons. First, they belonged to younger age-group, and second, they neither had breastfeeding experience nor they feel comfortable in breastfeeding their children. The use of contraceptives plays a role in lengthening inter-pregnancy interval, and thus, mothers have time to breastfeed their children, consequently reducing the risk of termination.

Region of residence of the respondents had a significant effect on the risk of termination of breastfeeding, for example, mothers from Chittagong were more likely to terminate breastfeeding than those from Sylhet. This is in agreement with the results of previous studies $(10-11,30)$. One of the key determinants of the decline in breastfeeding in Bangladesh is the increasing level of education of mothers, a factor which plays a role in the adoption of modern ideas and which usually leads to the abandonment of traditional practices regarding childcare. A similar trend that higher education is associated with shorter duration of breastfeeding was also observed in some earlier studies in Bangladesh (10-11) and in other developing countries (34), although the scenario in industrialized countries, such as Denmark, appears to be the opposite (35). Results of a study suggest that education is a proxy for socioeconomic status, which could be related to exposure to advertisements and the capability to buy infant formula (36). The probability of terminating breastfeeding by Muslim mothers was higher compared to non-Muslim mothers (Hindu, Christian, and Buddhist). Working women breastfed for a slightly longer duration compared to the non-working women, which is consistent with the findings of other studies $(30,32)$. Women in Bangladesh are involved in traditional or informal work (agricultural activities, domestic work, jobs in cottage industries, and small-scale marketing, or as labourer), especially in the rural areas, and have more flexible schedules, and this allows them to nurse their infants more often, thus maintaining longer periods of lactation.

The results of the present study indicate that the breastfeeding-promotion programme in Bangladesh should address mothers with higher education, those who have higher parity, give birth by caesarean section, and those living in urban areas and Chittagong since these mothers tend to breastfeed their children for a relatively-shorter period of time.

\section{ACKNOWLEDGEMENTS}

The authors thank the anonymous reviewers of this journal for providing insightful comments and suggestions for revision. 


\section{REFERENCES}

1. Heinig MJ, Dewey KG. Health advantages of breastfeeding for mothers: a critical review. Nutr Res Rev 1997;10:35-56.

2. Aryal TR. Some techniques to estimate child mortality in Nepal. J Inst Sci Technol 2004;13:48-61.

3. Ronsmans C, Chowdhury ME, Dasgupta SK, Ahmed A, Koblinsky M. Effect of parent's death on child survival in rural Bangladesh: a cohort study. Lancet 2010;375:2024-31.

4. Caldwell JC, Caldwell P. The role of marital sexual abstinence in determining fertility: a study of the Yoryba in Nigeria. Popul Stud 1977;31:193-217.

5. Morisky DE, Kar SB, Chaudhry AS, Chen KR, Shaheen $\mathrm{M}$, Chickering K. Breast feeding practices in Pakistan. Pakistan J Nutr 2002;1:137-42.

6. Aryal TR. Breastfeeding in Nepal: patterns and determinants. JNMA J Nepal Med Assoc 2007;46:13-9.

7. Lande B, Andersen LF, Baerug A, Trygg KU, LundLarsen K, Veierød MB et al. Infant feeding practices and associated factors in the first six months of life: the Norwegian infant nutrition survey. Acta Paediatr 2003;92:152-61.

8. Nolan L, Goel V. Sociodemographic factors related to breastfeeding in Ontario: results from the Ontario health survey. Can J Public Health 1995;86:309-12.

9. Michaelsen KF, Larsen PS, Thomsen BL, Samuelson G. The Copenhagen cohort study on infant nutrition and growth: duration of breastfeeding and influencing factor. Acta Paediatr 1994;83:565-71.

10. Giashuddin MS, Kabir M. Breastfeeding duration in Bangladesh and factors associated with it. Indian $J$ Commun Med 2003;28:34-8.

11. Giashuddin MS, Kabir M. Duration of breastfeeding in Bangladesh. Indian J Med Res 2004;119:267-72.

12. Killersreiter B, Grimmer I, Bührer C, Dudenhausen JW, Obladen M. Early cessation of breast milk feeding in very low birthweight infants. Early Hum Dev 2001;60:193-205.

13. Akin JS, Bilsborrow R, Guilkey DK, Popkin BM, Benoit D, Cantrelle P et al. The determinants of breastfeeding in Sri Lanka. Demography 1981;18:287-307.

14. Jain AK, Bongaarts J. Breastfeeding patterns, correlates and fertility effects. Stud Fam Plann 1981;12:79-99.

15. Islam S, Yadava KNS, Alam MA. Differentials and determinants of the duration of breastfeeding in Bangladesh: a multivariate analysis. Proc Pakistan Acad Sci 2006;43:1-14.

16. Arenz S, Rückerl R, Koletzko B, von Kries R. Breastfeeding and childhood obesity-a systematic review. Int J Obes Relat Metab Disord 2004;28:1247-56.
17. Harder T, Bergmann R, Kallischnigg G, Plagemann A. Duration of breastfeeding and risk of overweight: a meta-analysis. Am J Epidemiol 2005;162:397-403.

18. Owen CG, Martin RM, Whincup PH, Davey-Smith G, Gillman MW, Cook DG. The effect of breastfeeding on mean body mass index throughout life: a quantitative review of published and unpublished observational evidence. Am J Clin Nutr 2005;82:1298307.

19. Owen CG, Martin RM, Whincup PH, Smith GD, Cook DG. Effect of infant feeding on the risk of obesity across the life course: a quantitative review of published evidence. Pediatrics 2005;115:1367-77.

20. Bradley RH, Corwyn RF. Socioeconomic status and child development. Annu Rev Psychol 2002;53:37199.

21. Halldórsson M, Kunst AE, Kohler L, Mackenbach JP. Socioeconomic inequalities in the health of children and adolescents: a comparative study of the five Nordic countries. Eur J Public Health 2000;10:281-8.

22. Hjern A, Bremberg S. Social aetiology of violent deaths in Swedish children and youth. J Epidemiol Commun Health 2002;56:688-92.

23. Fairley L, Leyland AH. Social class inequalities in perinatal outcomes: Scotland 1980-2000. J Epidemiol Community Health 2006;60:31-6.

24. von Rueden U, Gosch A, Rajmil L, Bisegger C, RavensSieberer U. Socioeconomic determinants of health related quality of life in childhood and adolescence: results from a European study. J Epidemiol Community Health 2006;60:130-5.

25. Lawless JF. Statistical model and methods for life time data. $2 \mathrm{~d}$ ed. New York, NY: John Wiley and Sons, 1982:342-400.

26. SPSS Inc. SPSS for Windows (verson 10.0). Chicago: SPSS, Inc., 1999.

27. Lee ET, Wang JW. Statistical methods for survival data analysis. 3rd ed. Hoboken, NJ: John Wiley and Sons, 2003:64-97.

28. Sivakami M. The impact of maternal work participation on duration of breast feeding among poor women of South India. Asia-Pacific Popul J 2003;18:69-90.

29. Allison PD. Event history analysis: regression for longitudinal event data. Beverly Hills, CA: Sage, 1984;46:33-66. (Series quantitative applications in the social sciences).

30. Cox DR. Regression models and life tables (with discussion). J R Statist Soc (Series B) 1972;34:187-220.

31. Mannan HR, Islam NM. Breast-feeding in Bangladesh: patterns and impact on fertility. Asia Pac Popul J 1995;10:23-38. 
32. Ferry B, Smith DP. Breastfeeding differentials. Voorburg: International Statistical Institute, 1983:1-89. (World fertility survey comparative studies no. 23).

33. Ahmed MM. Breastfeeding in Bangladesh. J Biosoc Sci 1986;18:425-34.

34. Neville MC, Keller R, Seacat J, Lutes V, Neifert M, Casey $\mathrm{C}$ et al. Studies in human lactation: milk volumes in lactating women during the onset of lactation and full lactation. Am J Clin Nutr 1988;48:1375-86.
35. Grummer-Strawn LM. The effect of changes in population characteristics on breastfeeding trends in fifteen developing countries. Int J Epidemiol 1996;25:94102.

36. Vestermark V, Høgdall CK, Plenov G, Birch M, Toftager-Larsen K. The duration of breast-feeding: a longitudinal prospective study in Denmark. Scand J Soc Med 1991; 19:105-9. 